\title{
Proposal of an Innovative Business Model for Customized Production in Healthcare
}

\author{
Golboo Pourabdollahian, Giacomo Copani \\ Institute of Industrial Technologies and Automation (ITIA), National Research Council (CNR), Milan, Italy \\ Email: Golboo.pourabdollahian@itia.cnr.it
}

Received 11 October 2014; revised 13 November 2014; accepted 25 November 2014

Copyright @ 2014 by authors and Scientific Research Publishing Inc.

This work is licensed under the Creative Commons Attribution International License (CC BY).

http://creativecommons.org/licenses/by/4.0/

\section{(c) (i) Open Access}

\begin{abstract}
The growth of aging population in developed countries necessitates a better performance of the healthcare system in order to improve the healthy life expectancy of elderly people. Such a progress can be achieved both through improved services and medical products. Accordingly, providing patients with customized medical devices that are designed and produced based on individual requirements of each patient can be seen as a proper solution. In this regard, the emerging manufacturing technologies such an additive manufacturing not only facilitate customized production in healthcare sector, but also can change the role of the hospital from a solely user to a producer. However, successful pursuit of such strategy requires implementation of a new business model as a supporting tool. This paper aims at proposing an innovative business model to support hospitals for customized production in healthcare.
\end{abstract}

\section{Keywords}

Business Model, Customization, Healthcare, Manufacturing

\section{Introduction}

The aging population is increasing around the world. Although the growth rate is bigger in developed countries but the phenomenon is considered as a global issue. In this regard, Italy is considered as one of the oldest countries in the world. Having the life expectancy of 81.77 years, Italy has been ranked as the $7^{\text {th }}$ country in terms of life expectancy [1]. Having a deeper look on the past data, it can be seen that the life expectancy in Italy has an increasing trend by growing from 74 years in 1990 to 77 years in 2000 and eventually 82 years in 2013. According to existing data, in 2010, 20.2\% of Italians aged over 60. It is estimated that this amount would rise to $34.6 \%$ in 2030 and $38.7 \%$ in 2050 [2]. Although the length of lives in many countries has been increased, but still there is a gap between lifespan and health span. The healthy life expectancy is an indicator which shows the 
average number of years a person aged over 60 can expect to live in a good health. For Italy this amount is equal to 18.5 years indicating a 3.5-year gap with the life expectancy [2]. This data highlights an increasing number of elderly Italians who require an intensive healthcare service. Consequently, not only the healthcare management matters a lot, but also high quality medical devices and products which can increase the quality of life of elderly people and patients are quite important. Thereafter, usage of personalized medical products which can bring better function and hence better quality of life to patients thanks to their technical features which are designed based on individual requirements and need of each patient can be seen as a proper approach.

While personalization in B2C market and recently B2B market has been the center of attention of scholars and industries within the last decade, no major attention has been paid to the field of medical products. Indeed, the very few existing studies are investigating personalization in the level of healthcare management or medications [3] rather than production. A potential reason might relate to the lack of enabling technologies to facilitate customized fabrication of medical products and devices. A medical device directly affects the quality of life of a person and consequently becomes a more critical product in terms of production and quality criteria compared to the other consumables. Therefore, the technology should enable not only a precise conversion of patient's requirement to the product technical features and characteristics but also a high-quality production of the designed customized product.

In the recent years, the quick improvement of emerging technologies such as rapid prototyping, 3D printing and micro manufacturing opens up new stream of research in terms of customized production. In fact, these technologies can be seen as proper enablers for production of customized products including medical devices and specifically implantable medical products. Moreover, thanks to the emerging technologies which can facilitate manufacturing of customized medical products in a more efficient and quick manner, the role of hospital can change from a solely user of these products to a producer of customized medical devices. The new approach can be considered as a win-win strategy where the patient benefits a better service due to having a medical product which is designed based on his specific requirements; and the hospital benefits from offering a premium value proposition to the patients, getting a better brand reputation and also generating a potential source of revenue through being a producer. However, such a shift requires designing a new and innovative business model which can be implemented by the hospital for successful pursuit of such a strategy.

This paper aims at targeting this gap by developing an innovative business model for fabrication of customized medical devices considering the hospital as the potential producer. The proposed business model acts as a supporting tool for major strategic decision in terms of production of customized medical devices. Giving the role of manufacturer to the hospital, the developed business model highlights an innovative approach through providing value not only for the patients through a quicker and customized product and service, but also to the hospitals through generation of new competitive advantages for them which can eventually be considered as a source of revenue.

In the next parts, first a critical review of literature in terms of business model is presented. Thereafter the proposed business model structure will be defined and different configuration of the business model will be discussed.

\section{Business Model in Literature}

\subsection{What Is a Business Model?}

Over the past few years, "business model" has been emerged as a prevalent term in many publications in the field of management. Although the term has become a fashionable trend and has got much of attention, but there is still confusion about what exactly a business model is and how it can be used by companies. In fact, how a company can differentiate the terms "business model" and "strategy"; and consequently build a business model to pursue a specific strategy is still a challenging issue.

From the very early emergence of the term "business model” by Jones in 1960 [4], different definitions have been suggested to explain the term and its role. These definitions reflect various perspectives which can be covered by a business model; such as value creation, simplification of a complex system, money generation, company behavior representation, etc. In the late 90's Timmers presented one of the first structured, but still simple, definitions of business model [5]. He described business model as a general architecture for the product, service and information flow. Later, Petrovic, Kittl and Teksten [6] followed the same logic of Linder and Cantrell [7] to introduce value creation as the main role of a business model. Magretta [8] and Stähler [9] took a further step 
by differentiating "business model” from "strategy". They described a business model as a system that illustrates how different pieces of a business can fit together to pursue a specific strategy. In 2004, Osterwalder presented his broad definition when he stated, "business model is a conceptual tool that contains a set of elements and their relationships and allows expressing a company's logic of earning money. It is a description of the value a company offers to one or several segments of customers and the architecture of the firm and its network of partners for creating, marketing and delivering this value and relationship capital, in order to generate profitable and sustainable revenue streams" [10]. Later Osterwalder and Pigneur proposed a business model canvas as a tool to realize the previous definition of business model [11]. In this study, we see business model as a tool containing a set of strategic choices and alternatives to support a company to create, deliver and capture different forms of value within a value chain.

In the following sections, we will show the results of a broad literature review we carried out in the scope of this paper and in the fields of customization, healthcare and manufacturing.

\subsection{Business Model for Personalization, Customization and Mass Customization}

In the recent years the terms "Personalization", “Customization” and "Mass Customization" have been increasingly discussed and obtained attention as emerging trends and potential strategies for the companies. While Mass Customization is quite differentiated from the two other terms through focusing on both individualization and efficiency, it is quite very difficult to distinguish between personalization and customization. While some researchers differentiate the terms [12]-[15], others use them interchangeably [16] [17]. In this section we briefly introduce each term and thereafter we will have a critical review of literature in terms of existing business models and strategies to support personalization, customization and Mass Customization.

The concept of personalization refers to providing a tailored offer to the right customer at the right moment and in the right place [18]. The term has been also labeled with different authors as "individualization" [19] and "one-to-one marketing" [17]. Going through literature, personalization is mainly seen as a marketing concept where the company treats different customers in different ways. Therefore it can be considered as an enterprise-initiated strategy where the company knows the customers and their diversified needs, and therefore tries to offer the individualized product and services through interacting with them in order to learn about their specific desire [17] [20]. Vesanan and Raulasempha size more on the marketing aspect of personalization as a marketing process which is not only about individualized products and services but also individualized communication, price and delivery [21]. Some other authors follow the same approach to define personalization suggesting that it might encompass any part of marketing mix such as product, price, place and promotion [12] [22].

Customization, on the other hand, has been defined diversely by different authors. While some studies use the term interchangeably with personalization, others have not considered it identical with personalization. Peppers, Rogers and Dorf emphasize on the customer interaction defining the term as treating a customer in an individualized manner based on his/her request during the interaction with the firm [23]. Hanson defined customization as a part of personalization where individual information and the flexible product designed are combined [24]. Imhoff, Loftis \& Geiger followed the same approach of Hanson by considering customization as a sub-level personalization which includes individualization of the product attributes and features [25]. Some other studies focus on the role of customer during the customization process. On the other hand, they believe that customization is a consequence of customer interaction. Coner defines customization as a personalization process which is carried out by the user instead of the company [26]. Wind \& Rangaswamy take a step forward by rephrasing the term to "customerization" in order to emphasize on the role of customer [27]. Consequently, despite of many similarities between the two terms of personalization and customization, they have distinctive differences. While personalization can be seen as an individualization strategy which is initiated by the enterprise, customization is a user-initiated strategy which is mainly focused on the company-user interaction. On the other hand while customization is mainly referred to tailoring the features of products or services, personalization follows a more general perspective through encompassing the other dimensions and specially the marketing one.

Beside the existing body of literature regarding customization, there is a growing number of studies focusing on Mass Customization. Although the idea of Mass Customization is not a brand-new idea, but in recent years it has got much attention from scholars in different fields. The initial idea of Mass Customization came to exist for the first time by Alvin Toffler in 1971 to respond to the needs of a post-industrial society, which he referred to as "third wave" [28]. A third wave society is characterized by a lot of diversity in lifestyle, adaptive and flexible 
organizations as well as extremely efficient and smooth information flow. According to Stan Davis who coined the term Mass Customization for the first time, MC is a process through which companies reach a large segment of the market, as they do in mass production, while they treat customers individually like as they do in a customized market [29]. Joseph Pine improved the definition by defining MC as a process through which a large variety of products are offered to customers at prices, which are comparable to the standard goods and services [30]. The concept was continuously evolved during time and by further definitions which were focused on operational perspective of MC [31], genus and basic elements of MC [32] and main capabilities for MC [33].

Apart from all definitions, the obvious point is that adoption of personalization and Mass Customization, like any other strategy, needs some major changes in different levels of a company. There are several key issues that should be addressed before and during the implementation of each strategy. These issues cover a wide range, varying from technological enablers to human resources and interaction with partners. A business model plays a critical role to elaborate such key issues. A business model acts as a conceptual tool to illustrate different alternatives and enablers as well as their possible links and interdependencies. It also elaborates how the internal processes of a firm can be designed and managed to facilitate an efficient operation while creating value for customers.

Despite of such a critical role of a business model, there are very few studies in literature investigating development of a proper business model for personalization, customization and Mass Customization. In the other words, the literature of personalization is mainly dedicated to conceptual definitions and marketing dimension of the term, so that there are extremely rare studies investigating the concept from a business model perspective. In terms of customization and MC, the literature is mainly directed toward Mass Customization through definition and identification of enablers and capabilities for successful implementation of MC. In any case, the majority of these studies are not focused on a business model but on development of frameworks or defining key success factors for personalization, customization, and Mass Customization.

\subsection{Business Model for Healthcare}

Health care is considered a quick evolving sector. Several global trends such as customization, aging population, e-healthcare and patient-oriented healthcare force the healthcare systems to develop very flexible business models which can be adopted quickly to the existing trends in the market. However, the challenging issue of development of the business model for the healthcare sector is not only related to its complicated and ever changing nature but also to its intense level of regulation. In most of countries, the healthcare system is a national system which is directly regulated and managed by the government or the government-related organizations. In such circumstances, having a proper business model for healthcare providers seems extremely critical since several stakeholders should benefit from such a model. In the other words, while a business model can assure the patients, hospitals and the government about a good quality service, it can also ensure the efficiency and cost-relevancy of the offered services. Nevertheless, despite of the important role of the business model for the sector, when it comes to the scientific and academic contents, there are very few supporting and relevant studies in the literature in this regard. In fact, the literature of healthcare is mainly focused on three main areas including healthcare management, healthcare cost and expenditure analysis, and healthcare supply chain management.

In 2012, King and Green carried out a study to understand the primary healthcare practices in the case of Australian healthcare through focusing on the governance structure in primary healthcare business [34]. In another study Faezipour and Ferreira investigated the healthcare management issues from a patient satisfaction perspective. Through their study they identified important factors and their causal relationships affecting the patient satisfaction and eventually the social sustainability level of the healthcare provider [35]. Nelson and Sen, proposed a framework to implement business rule management in healthcare industry in order to facilitate the changing of business processes and practices quickly and efficiently [36]. On the other hand, some authors have studied the healthcare business model concept from a financial and economic perspective [37] [38]. Other scholars have focused on the topic from a supply chain perspective. A notable study in this regard has been conducted by Dobrzykowski, Deilami, Hong, and Kim where a structured analysis has been carried out to analyze the literature in terms of operations management and supply chain management in healthcare sector [39]. Chen, Preston and Xia conducted an empirical study to identify the influencing factors on the healthcare supply chain performance [40].

Apart from the above mentioned studies, which can be related to the field of healthcare business model par- 
tially or in an indirect manner; there are also few studies which directly target the concept of healthcare business model. Recently Lehoux, Daudelin, Williams-Jones, Denis, and Longo conducted a research to explore the mutual impacts of the health technology design and the business model for healthcare [41]. As a result, they identified a set of business model elements that mediated the relationship between value creation and technology design in healthcare namely: key characteristics, value proposition, value chain, value capture, value network, transition between value offer and value capture. Another study by Van Liburgand van Gemert-Pijneninvestigates the development of innovative business models for sustainable e-healthcare applications. Taking into account the Osterwalder's business model canvas, the authors propose a tailored business model for e-healthcare containing of 9 business blocks of partner network, core capability, value configuration, value proposition, CRM, distribution channels, target customers, revenue model, cost structure [42].

\subsection{Business Model for Manufacturing}

The existing body of literature in terms of business model for manufacturing is quite broad and fragmented to several perspectives such as manufacturing sector and manufacturing systems.

While some authors conducted their study taking into account the general factors of manufacturing [43], others carried out research on specific sectors of manufacturing. Wiesner, Padrock and Thoben proposed a business model by focusing on 4 sectors namely consumer electronics, white goods, garments and machine tools [44]. Another study by Copani et al. was focused on development of machinery tools business model for European producers aiming at increasing the competitiveness of both system suppliers and end-users [45]. A study by Urbani, Molinari-Tosatti, and Pasek presents a categorization of new business models based on different factors: the "Ownership of equipment", the "Location of production", the "Responsibility for the operation of the equipment" and the "Responsibility for the maintenance of the equipment". In their categorization each of the dimensions can be adopted either by the equipment supplier or by the end user of the equipment [46]. Later, an exploratory empirical research in the field of new business concepts conducted by Lay, Meier, Schramm, and Werding revealed the necessity to enlarge the categorization scheme for new business concepts. Based on their proposal, besides ownership, location, operation and maintenance at least two more dimensions are crucial in order to shape and describe new business concepts in a comprehensive way: "mode of payment" and "number of customers" [47]. Afterwards, Copaniand Urgo improved the morphological box of Lay et al. outlining additional characteristic features and options, regarding the adopted technology and logistics aspects such as procurement of raw materials and transportation of manufactured products [48].

\section{Proposal of an Innovative Business Model for Customized Fabrication in Healthcare}

In order to propose an innovative business model for customized fabrication in healthcare, we consider the morphological box proposed by Lay, Meier, Schramm, and Werding as a reference model. This was mainly due to the fact that their proposed model, is very much focused on the manufacturing attributes and the strategic decision which should be made while designing a manufacturing business mode. Considering that the emphasis of this study is on production as well, the model is quite aligned with the main objectives of this research. As it is illustrated in Figure 1, the model consists of several characteristic features and several options for each characteristic feature. Besides the main strategic decisions in terms of production such as location of production, ownership of equipment, and operating personnel; the model covers two other dimensions related to modes of payment and number of customers. While "mode of payment" defines the cost structure of the business model, "number of customers" refers to the question if equipment in new business concepts is operated for a single customer or for multi customers in parallel. In their proposed model, ownership, location, operation and maintenance can be adopted not only by equipment suppliers or customers but also by operating joint ventures or leasing banks.

Although the model developed by Lay et al. is focused on manufacturing and hence is quite aligned with the objectives of this paper, but it does not cover all the dimensions of our study. Therefore, considering the peculiarities of the specific case of customized fabrication in healthcare, the model was modified to come out with a new model. The final business model structure outlines 6 main building blocks with different alternatives for each block. The building blocks of the business model include the most relevant variables for the configuration of a manufacturing system for the production of customized healthcare products. Figure 2 illustrates the struc- 


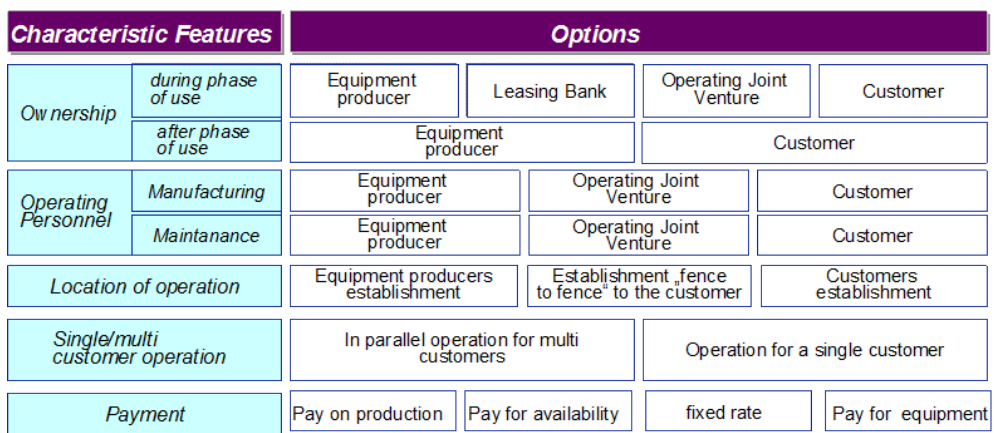

Figure 1. Business model structure proposed by Lay et al. (2003).

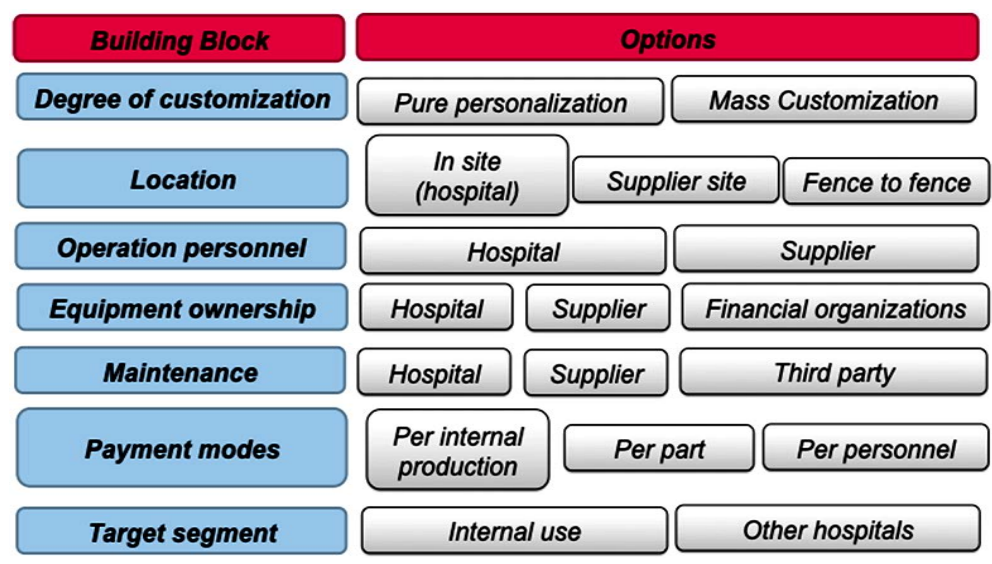

Figure 2. Business model structure.

ture of the proposed business model.

The building blocks of the business model are mainly defined to illustrate its characteristics features considering the scope of the research regarding production of customized medical products and taking into account the hospital as the potential manufacturer. Accordingly each building block refers to a specific dimension of a business model with the related supporting alternative for that dimension. As a result different configurations of business model can be developed through combination of different alternatives of each building block. A brief description regarding each block and its alternatives are given below:

- Degree of customization: is the initial building block of the business model structure. This building block is focused on the personalization dimension of the study. Based on the decision made in this step the final product will be either pure personalized or mass customized. The decision made at this level influences the final product features, cost and lead-time.

- Location: is the block investigating the physical location where the fabrication and production of customized medical products takes place. Accordingly, three main alternatives are defined for the location block: in-site, supplier site, and fence to fence. While in the first option the production takes place inside the hospital, in the second one all the fabrication processes are carried out in another company which is recognized as the supplier of the customized medical products for the hospital. Meanwhile, the third alternative suggests that production takes place in a plant located in the proximity of the hospital (fence-to-fence). The three alternatives of the location are later used to define the three main scenarios for the customized production.

- Operation personnel: refers to the human resource who are responsible to deal with the production equipment and machineries to produce the customized products. Taking into account that the current business model is developed considering the latest technological improvements in the field of customized production such as micro-manufacturing and 3D printing, a specific focus on the production personnel at the business model level is required. The two alternatives suggest that the operation personnel can be either from the hospital personnel or provided by the supplier company. 
- Equipment ownership: indicates to the entity who owns the production equipment which can be the hospital, the supplier company, or a financial organization.

- Maintenance: defines the different actors who can be responsible of the maintenance of the production facilities. Consequently, the maintenance can be performed by the hospital itself, or by the supplier company. As a third alternative, it can be also outsourced to a third-party.

- Payment modes: deals with the financial aspect of the business model identifying how the hospital would pay the cost. As a first option, the cost can be paid per internal production where the production takes place in-site or in a fence-to-fence situation. However, in the case that the production takes place in the supplier's site, the hospital pays per each unit of the product they purchase. As an additional option, the cost can be paid per personnel too.

- Target segment: There are mainly two segments which can be targeted to use the produced customized products. The products are either used internally only by the hospital or can be also sold to the other hospitals. This extremely depends on the decisions made in previous blocks.

\section{Pure Personalization Configurations vs. Mass Customization Configurations}

While pursuing pure personalization, the produced medical device will be designed and produced after identifying the exact characteristics and dimensions for each patient. Therefore it will be extremely individualized based on each patient's requirements. For instance in the case of a coronary stent, the stent can only be produced after defining of the dimensions and characteristics of the stent by the surgeon based on the patient's condition and requirements. Upon arrival of the information, the design phase starts when a CAD design of the stent is made. Moreover, based on the request of the surgeon a prototype of a part of the patient's cardiovascular system where the stent will be implanted can be produced. The prototype which represents the exact dimensions and characteristics of the patient's veins can be used by the surgeon to test the function and performance of the produced individualized stent. The pure personalized stent can benefit the patient through having a better performance and improving his/her conditions thanks to its personalized features. Nevertheless, in comparison with standard stents, it takes more time to retrieve the required data for each patient, design the product and finally manufacture it. This issue can be critical especially in the case of emergency operation when time is an extremely vital factor.

Selection of Mass Customization as the proper degree of customization to fabricate the medical product would lead to generation of different alternatives of business models compared to pure personalization. The change, however, does not relate to selection of different combinations of option for different characteristic features of the business model, but to the level of variety and number of customized variants which are offered to patients. In the other words, while in pure customization every single patient benefits from a unique individualized product; in Mass Customization a designed customized product might serve several patients. This is mainly related to the concept of solution space in Mass Customization. The term "solution space" is popularized by Piller as one of the main pillars of Mass Customization [32]. Salvador, De Holan and Piller indicate "solution space development" as one of the key capabilities for Mass Customization [33]. Considering that one of the main goals of each MC company relates to its ability to identify customers' heterogeneous needs and fulfill them with proper and appropriate offerings, therefore the company should define the boundaries of its offering and all possible variants to the customers. Such a space is called solution space where a manufacturer clearly defines what is offered to customers and what is not. Defining an appropriate solution space is a challenging task. Setting wrong dimensions for a solution space can lead a MC company to fail. In order to reach a proper solution space, it is necessary to define the customization dimensions as well as the level of variety for each dimension. MC implies by necessity the development of vast solution spaces, thus escalating the cost and complexity of understanding customer needs, in terms of spotting differentiating attributes, validating product concepts, and collecting customer feedback.

Coming back to the case of stent fabrication, a solution space can be defined in order to identify the level of variety which is offered to the patients. In this case, the surgeon can select the best-fitted stent within the solution space considering the requirements of each patient. To this end a configurator is used which helps the surgeon to navigate the solution space. Configuration systems are something wider than a simple computer tool. The software interacts with the personnel at least in the initial and final stage of the configuration [49]. A Design Configurator thus enlarges the solution space from where all the product variations can be thought to originate. 
It enables almost infinite variations within the defined borders of the product specifications, which have been parameterized. Conceptually, the design configurator handles the entire order engineering process. It receives the input from surgeon, develops the design using pre-defined CAD models, and transfers the output to production. Its main contribution is automating the design stage in order engineering, which shortens the engineering lead-time. Automation can also lead to fewer design mistakes caused by human error and reduce repetitive manual work. Through the usage of configurators the patient's requirements can be efficiently converted to a technical product individual specification. The ultimate target of this conversion is to achieve a correct list of technical item codes to be produced. The configurator allows the surgeon to find the possible combinations of stents and guides him/her trough the configuration process with different design options. The specific designs are stored in the configurator and reused when needed. All this process, eventually, results in a shorter lead-time and lower cost compared to pure personalization.

\section{Definition of Potential Configurations of the Proposed Business Model}

Upon selection of the degree of customization, we define three main scenarios to come out with different configurations of the business model. These scenarios are based on the location of production having three possible alternatives: Internal production, fence-to-fence production, and external production. Having these three scenarios, different configurations of business model can be developed through combination of options in the other building blocks. In the next parts, we describe potential business model configurations for each scenario.

\subsection{Scenario 1: Internal Production}

In this scenario, the production facilities and equipment are located inside of the hospital. Such a decision results in some benefits such as a shorter lead-time, brand reputation, no shipment cost, and an easier and more frequent interaction of medical staff during the co-design process. Nevertheless, it can also results in some challenges. The main challenge is that operating a production plant inside of a hospital requires a complete compliance to the strict standards of the hospital in terms of cleanliness since having such a plant can be considered as source of contamination. Beside, the hospital needs to do the certification process to get the required certificates to produce the medical devices.

Four main configurations of business model which can be defined in this scenario are hospital-operating lab, supplier-operating lab, and hybrid operating lab (including two configurations). Each configuration is briefly described in the following.

Personalized/MC hospital-operating lab: In this business model (Figure 3), the human resources to operate the lab are employed by the hospital. The ownership of the production facilities and equipment can belong to the hospital or to some financial organizations such as banks. The maintenance of the equipment can be carried out either by the hospital personnel or through sub-contracting a third party. In such a business model, since the production lab is owned and operated by the hospital, the payments will be done per internal production and considering all the production cost. As an advantage, the hospital plays the role of a supplier for other hospitals by providing them their required personalized products.

Personalized/MC supplier-operating lab: In contrary to the previous business model where hospital was the main player in the production, in this configuration the hospital is only considered as the owner and location of the production. This means that all the other processes will be carried out by an external supplier. The supplier not only provides the machinery and equipment for the customized production, but also has its own operation personnel for the production processes. In most cases, the maintenance of the machines is done by the supplier itself, however it can be also done by sub-contracting a third-party. Since all the operations are carried out by the supplier, the hospital pays for each final product they receive. Nevertheless, the lab not only can be used to produce the internal need of the hospital but also to manufacture the received orders of the other hospital and external entities (Figure 4).

Personalized/MC hybrid-operating lab: The hybrid-operating business model considers both the hospital and the suppliers as the active players in the production process. A potential hybrid business model shown in Figure 5(a) illustrates how the production can be carried out. Like the previous business models, in this case the production of the pure personalized products takes place inside of the hospital and by having hospital personnel as the human resource for operation. However, the equipment is not owned by the hospital but by the suppliers. The hospital rents the facilities and machines and the supplier is responsible for the maintenance. The payment 


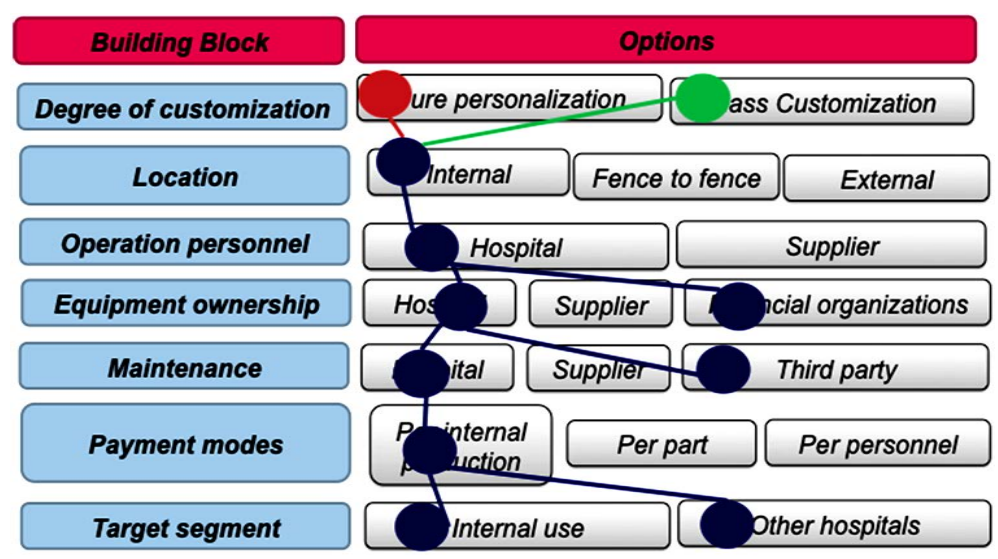

Figure 3. Pure personalized/MC hospital-operating lab.

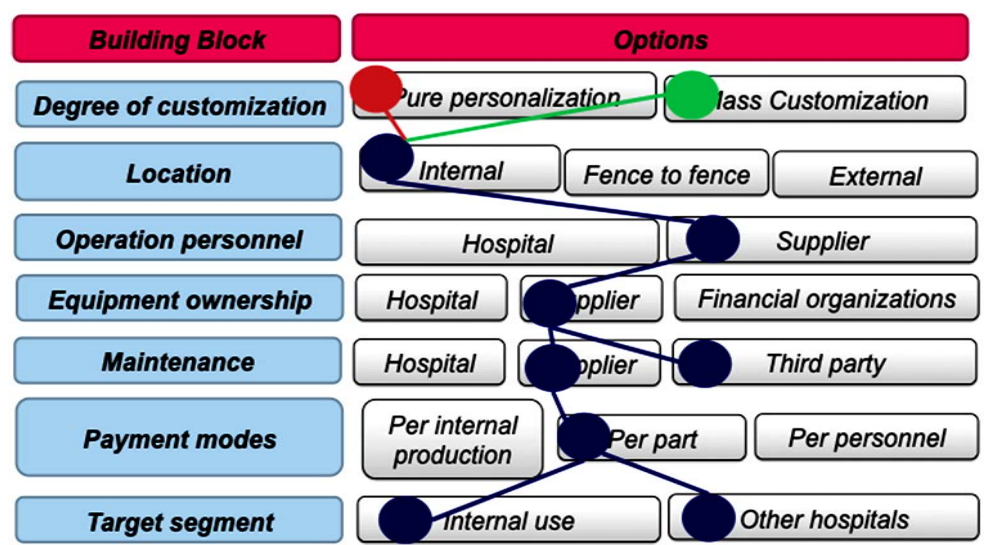

Figure 4. Pure personalized/MC supplier-operating lab.

is per internal production and like previous cases the produced products can target both internal and external customers.

Another possible hybrid business model is shown in Figure 5(b). In this case, the hospital (or a third financial organization) owns the equipment of the hospital production lab, however; the operation is carried out by the supplier's personnel. Such a configuration is beneficial in case that the hospital lacks the qualified and expert personnel to operate the machines and equipment. The maintenance is done by the hospital or by a third party and the payment to the supplier is done per personnel. The final product can be used internally and be sold to the external customers.

\subsection{Scenario 2: External Production}

In this scenario the production takes place at another company that acts as the supplier of the customized medical devices. Following the identification of the characteristics of the medical product, the hospital places an order to the manufacturer. The final product will be produced at the supplier site and will be shipped to the hospital. In this scenario the hospital benefits through avoiding any investment and certification process. However, this brings a low negotiation power to the hospital due to loss of control and dependency to the suppliers. It also increases the risk of suppliers lobbying. Moreover the lead-time and final cost will be increased compared to the previous scenario.

The potential configuration is defined highlighting the supplier as the key player.

Personalized/MC order placement: The order placement configuration is based on the idea that the production of the product occurs at the supplier site. In this case, the supplier owns the equipment and machinery, is responsible for their maintenance and has its own personnel to carry out the operation. The payment is done for each ordered product. In contrary to the previous scenario of internal production, the final product can be used 
only internally by the hospital considering that the hospital is not the producer but the consumer of the medical device. Figure 6 represents the structure of this configuration.

\subsection{Scenario 3: Fence-to-Fence Production}

The scenario of the fence-to-fence production suggests that the production takes place neither inside of the hospital nor at supplier's site but it occurs in a production plant in proximity of the hospital. Therefore, although the

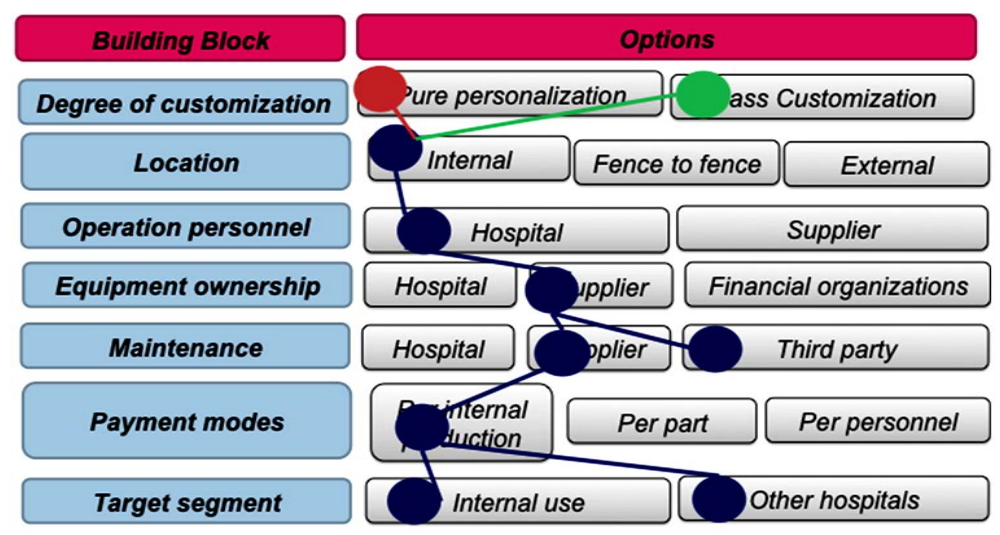

(a)

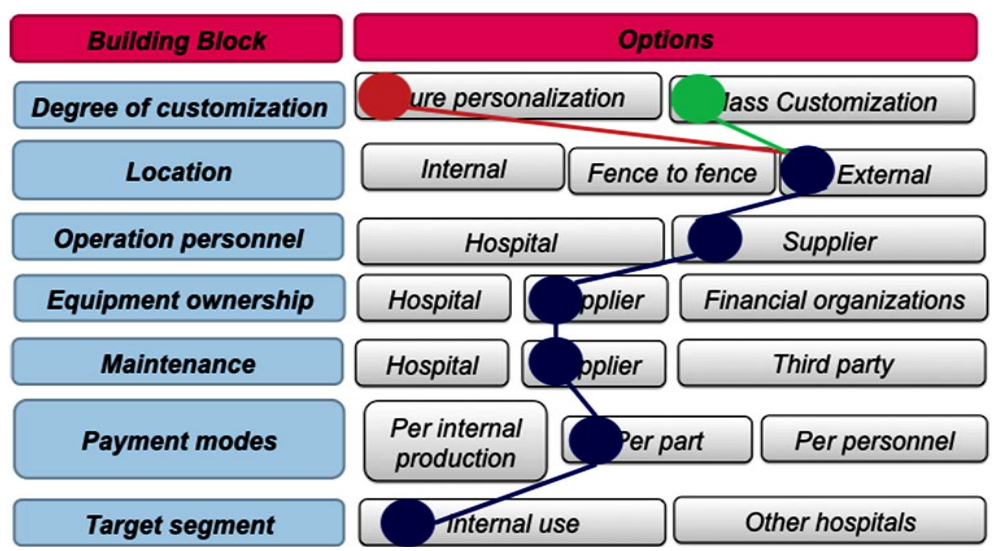

(b)

Figure 5. (a) Pure personalized/MC hybrid-operating lab; (b) Pure personalized/MC hybrid-operating lab.

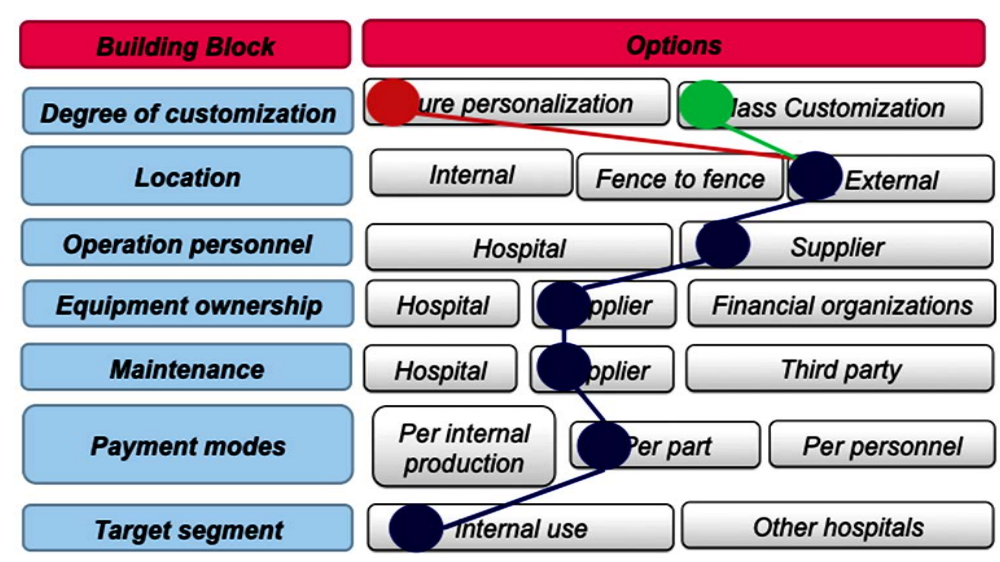

Figure 6. Pure personalized/MC order placement. 
plant is not located inside of the hospital but it is close enough to have the benefits of an internal production. In the case of fence-to-fence production, there is less limitation in terms of plant capacity compared to the internal scenario and hence the hospital can benefit from economy of scale as well as other advantages of internal production such as brand reputation and a shorter lead-time. Moreover the main present challenge in Scenario 1 regarding the contamination issue is not a challenge anymore. The fur potential configurations of business model in this scenario are presented in following.

Fence-to-fence pure personalized/MC hospital-operating lab: Similar to the first configuration in scenario 1 (Figure 7), this configuration emphasizes on the role of the hospital as the main player so that the ownership, maintenance and operation processes are all handled by the hospital.

Fence-to-fence pure personalized/MC supplier-operating lab: In this configuration of business model, the fence-to-fence production lab belongs to the hospital but is run by the supplier. In the other words, the hospital rents the equipment and the supplier carries out the production having its own personnel. The maintenance is done by the supplier as well. Consequently the hospital pays the supplier per each produced part. The final products can be used internally and sold to the external customers (Figure 8).

Fence-to-fence pure personalized/MC hybrid-operating lab: In this configuration, the production of the final products is carried out by the supplier personnel but the equipment is owned by the hospital. The payment takes place per personnel and the final prosthesis can be targeted to other hospitals as well as being used internally (Figure 9).

\section{Conclusion}

The aging population around the world is increasing as a consequence of an increased life expectancy. Currently this trend is higher in developed countries but it is becoming a global issue. One of the direct consequences of

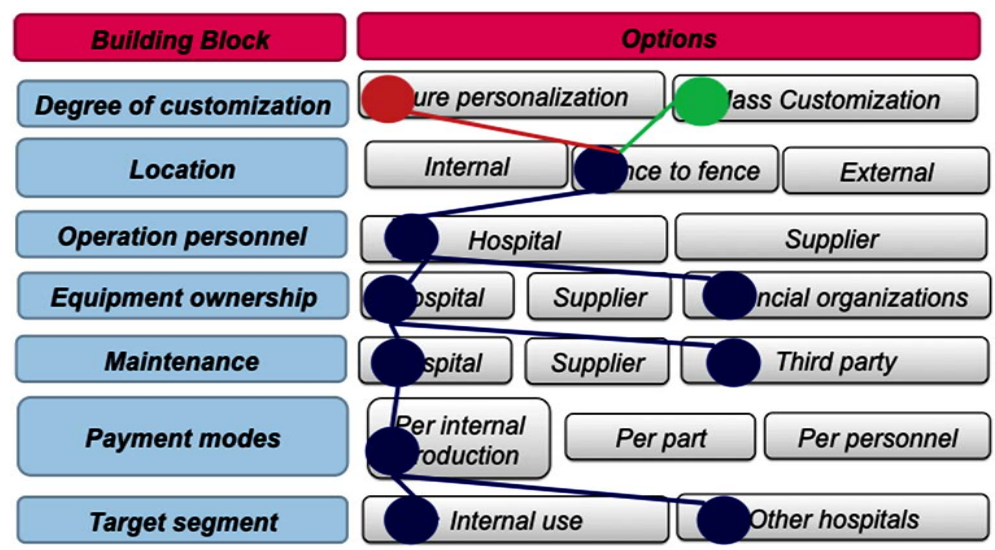

Figure 7. Fence-to-fence pure personalized/MC hospital-operating lab.

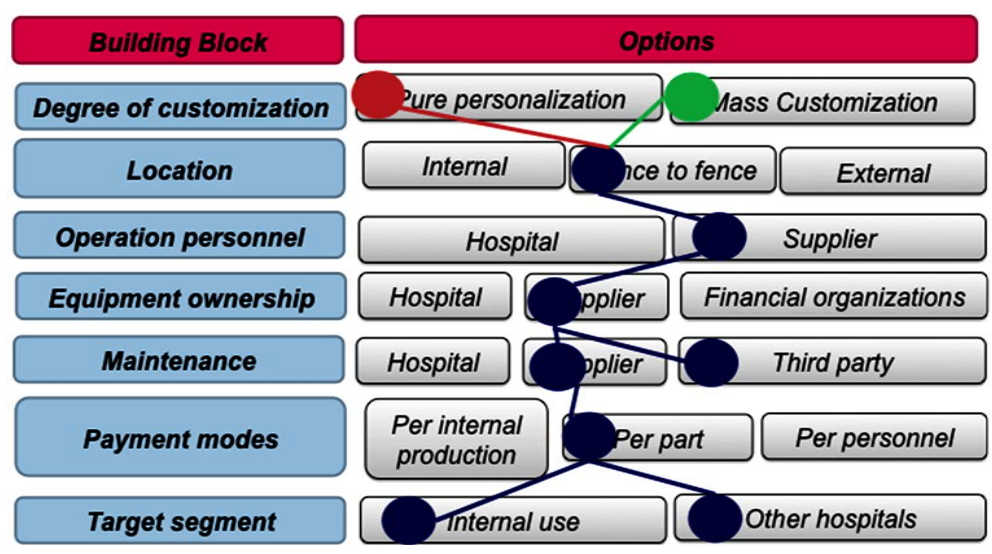

Figure 8. Fence-to-fence pure personalized/MC supplier-operating lab. 


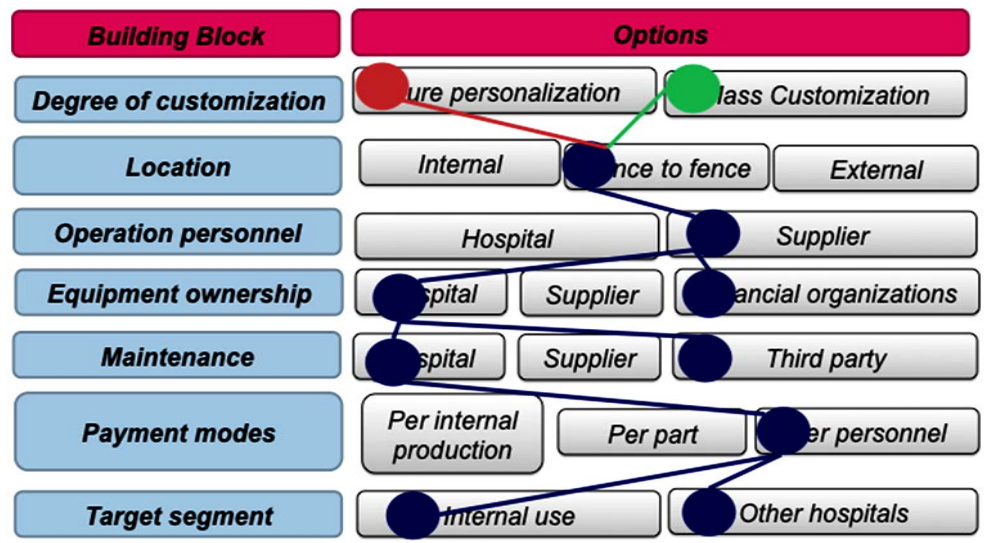

Figure 9. Fence-to-fence pure personalized/MC hybrid-operating lab.

this phenomenon, relates to the healthcare system where a better service is required to decrease the gap between the life expectancy and the healthy life expectancy through improving the quality of life of elderly people. To this end, medical products which are designed based on individual requirements of each patient can result in a better treatment or quality of life. Such a result depends on successful introduction and implementation of customization in healthcare and specifically in the field of medical device production.

In the last two decades customization has been broadly discussed as a potential business model for heterogeneous markets in management literature [50]. In the market settings that are characterized by high levels of customer need heterogeneity, customization has to be considered as a proper strategy. On one hand, firms can charge higher prices for customized goods because of the increased willingness to pay of customers for individualized goods. On the other hand, realization of additive manufacturing technologies, flexible manufacturing processes and suitable customer interaction tools allow providing these customized goods at cost levels that are comparable to those of mass produced goods. However, a critical factor is the degree of customization, which every firm decides to offer. While some on offering pure personalized products, there are others that pursue Mass Customization. The two options lead to different levels of cost and time as well as the final target segment of customers. While in the case of personalization the product is completely designed and engineered based on the requirements of the customer, but it costs more and requires a longer lead-time. Nevertheless, implementing MC, the customization will be limited to the product varieties within a defined solution space thus a lower level of customization compared to pure personalization, but with a lower cost and shorter lead-time.

Coming back to the case of customization of medical products, there is an absolute need of introducing a new business model for successful pursuit of the idea. In this study we tried to target this gap by designing an innovative business model structure for fabrication of customized medical devices. The proposed business model is not only focused on the value proposed to the patients, but also on the critical factors influencing the production of such customized products such as location, equipment ownership, etc. The proposed model then was used as a reference structure to define several configurations of business model through combining the different options in each block of business model. Each configuration suggests a new business model which can be pursued by hospitals to fabricate customized medical products.

It should be mentioned that the proposed model, is a theoretical model and therefore its implementation require further steps such as economic assessment of the model. This study provides the initial step towards introducing the hospital as a potential manufacturer of customized medical products through development of a business model for customized production of medical devices. However, as an emerging research stream, the field still requires further investigations, analysis and studies by other researchers to realize such a business model in practice.

\section{Acknowledgements}

This work is funded by Italian Ministry of Education, University and Research (MIUR) and National Research Council of Italy (CNR) through the research program "Factory of the Future-S2" (Research Project Fab@Hospital). The authors would like to thank MIUR, CNR, and all the participating organizations for sharing their insights in 
the study.

\section{References}

[1] WHO (2014) WHO Life Expectancy. WHO, Geneva.

[2] Global Age Watch Index (2014) Global Age Watch. http://www.helpage.org/global-agewatch/

[3] Minevielle, E., Waelli, M., Sicotte, C. and Kimberly, J.R. (2014) Managing Customization in Health Care: A Framework Derived from the Services Sector Literature. Health Policy, 117, 216-227. http://dx.doi.org/10.1016/j.healthpol.2014.04.005

[4] Jones, G.M. (1960) Educators, Electrons, and Business Models: A Problem in Synthesis. Accounting Review, 35, 619626.

[5] Timmers, P. (1998) Business Models for Electronic Markets. Electronic Markets, 8, 3-8. http://dx.doi.org/10.1080/10196789800000016

[6] Petrovic, O., Kittl, C. and Teskten, R.D. (2001) Developing Business Models for E-Business. International Conference on Electronic Commerce, Vienna, 31 October-4 November 2001.

[7] Linder, J. and Cantrell, S. (2000) Changing Business Models: Surveying the Landscape. Accenture Institute for Strategic Change. http://course.shufe.edu.cn/jpkc/zhanlue/upfiles/edit/201002/20100224120954.pdf

[8] Magretta, J. (2002) Why Business Models Matter. Harvard Business Review, 80, 86-92.

[9] Stähler, P. (2002) Business Models as an Unit of Analysis for Strategizing. Proceedings of the International Workshop on Business Models, Lausanne, 4-5 October 2002.

[10] Osterwalder, A. (2004) The Business Model Ontology_A Proposition in a Design Science Approach. Ph.D. Dissertation, University of Lausanne, Lausanne.

[11] Osterwalder, A. and Pigneur, Y. (2010) Business Model Generation. John Wiley \& Sons Inc., Hoboken.

[12] Arora, N., Dreze, X., Ghose, A., Hess, J.D., Iyengar, R. and Jing, B. (2008) Putting One-to-One Marketing to Work: Personalization, Customization, and Choice. Marketing Letters, 19, 305-321. http://dx.doi.org/10.1007/s11002-008-9056-z

[13] Gilmore, J.H. and Pine, J. (1997) The Four Faces of Mass Customization. Harvard Business Review, 75, 91-101.

[14] Kumar, A. (2007) From Mass Customization to Mass Personalization: A Strategic Transformation. International Journal of Flexible Manufacturing System, 19, 533-547. http://dx.doi.org/10.1007/s10696-008-9048-6

[15] Montgomery, A.M. and Smith, M.D. (2009) Prospects for Personalization on the Internet. Journal of Interactive Marketing, 23, 130-137. http://dx.doi.org/10.1016/j.intmar.2009.02.001

[16] Miceli, G.N., Ricotta, F. and Costabile, M. (2007) Customizing Customization: A Conceptual Framework for Interactive Personalization. Journal of Interactive Marketing, 21, 6-25. http://dx.doi.org/10.1002/dir.20076

[17] Peppers, D. and Rogers, M. (1997) The One-to-One Future. Double Day Publications, New York.

[18] Sunikka, A. and Bragge, J. (2012) Personalization of Online Communications in Online Financial Services. In: The Future of Banking Services, Unigrafia, Helsinki, 15-24.

[19] Riemer, K. and Totz, C. (2001) The Many Faces of Personalization-An Integrative Economic Interview of Mass Customization and Personalization. In: The Customer Centric Enterprise-Advances in Mass Customization and Personalization, Springer-Verlag, Heidelberg, 35-50.

[20] Adomavicius, G. and Tuzhilin, A. (2005) Personalization Technologies: A Process-Oriented Perspective. Communications of the ACM, 48, 83-90. http://dx.doi.org/10.1145/1089107.1089109

[21] Vesanen, J. and Raulas, M. (2006) Building Bridges for Personalization: A Process Model for Marketing. Journal of Interactive Marketing, 20, 5-20. http://dx.doi.org/10.1002/dir.20052

[22] Hong, J., Suh, E.H., Kim, J. and Kim, S.Y. (2009) Context-Aware System for Proactive Personalized Service Based on Context History. Expert Systems with Applications, 36, 7448-7457. http://dx.doi.org/10.1016/j.eswa.2008.09.002

[23] Peppers, D., Rogers, M. and Dorf, R. (1999) The One to One Field book: The Complete Toolkit for Implementing a 1 to 1 Marketing Program. Currency Doubleday, New York.

[24] Hanson, W. (2000) Principles of Internet Marketing. South Western, Cincinnati.

[25] Imhoff, C., Loftis, L. and Geiger, J. (2001) Building the Customer-Centric Enterprise, Data Warehousing Techniques for Supporting Customer Relationship Management. Wiley, New York.

[26] Cöner, A. (2003) Personalization and Customization in Financial Portals. Journal of American Academy of Business, 2, 498-504. 
[27] Wind, J. and Rangaswamy, A. (2001) Customerization: The Next Revolution in Mass Customization. Journal of Interactive Marketing, 15, 13-32. http://dx.doi.org/10.1002/1520-6653(200124)15:1<13::AID-DIR1001>3.0.CO;2-\#

[28] Toffler, A. (1970) Future Shock. Bantam, London.

[29] Davis, S. (1987) Future Perfect. Addison-Wesley, Harlow.

[30] Pine, B.J. (1993) Mass Customization-The New Frontier in Business Competition. Harvard Business School Press, Boston.

[31] Tseng, M.M. and Jiao, J.X. (2001) Chap. 25. Mass Customization. In: Salvendy, G., Ed., Handbook of Industrial Engineering: Technology and Operations Management, 3rd Edition, Wiley, New York, 684-709. http://dx.doi.org/10.1002/9780470172339.ch25

[32] Piller, F.T. (2004) Mass Customization: Reflection on the State of the Concept. International Journal of Flexible Manufacturing System, 16, 313-334. http://dx.doi.org/10.1007/s10696-005-5170-x

[33] Salvador, F., De Holan, P.M. and Piller, F.T. (2009) Cracking the Code of Mass Customization. MIT Sloan Management Review, 50, 71-78.

[34] Zine, P.U., Kulkarni, M.S., Chawla, R. and Ray, A.K. (2014) A Framework for Value Co-Creation through Customization and Personalization in the Context of Machine Tool PSS. Procedia CIRP, 16, 32-37.

[35] King, R. and Green, P. (2012) Governance of Primary Healthcare Practices: Australian Insights. Business Horizons, 55, 593-608. http://dx.doi.org/10.1016/j.bushor.2012.07.006

[36] Faezipour, M. and Ferreira, S. (2011) Applying Systems Thinking to Assess Sustainability in Healthcare System of Systems. International Journal of System of Systems Engineering, 2, 290-308. http://dx.doi.org/10.1504/IJSSE.2011.043861

[37] Nelson, M.R. and Sen, R. (2014) Business Rules Management in Healthcare: A Lifecycle Approach. Decision Support Systems, 57, 387-394. http://dx.doi.org/10.1016/j.dss.2012.10.044

[38] Manning, W.G. (2014) Modeling Cost and Expenditure for Healthcare. Encyclopedia of Health Economics, 299 -305.

[39] Bukh, P.N. and Nielsen, C. (2011) Understanding the Health Care Business Model: The Financial Analysts’ Point of View. Journal of Health Care Finance, 37, 8-26.

[40] Dobrzykowski, D., Deilami, V.S., Hong, P. and Kim, S.C. (2014) A Structured Analysis of Operations and Supply Chain Management Research in Healthcare (1982-2011). International Journal of Production Economics, 147, 514-530. http://dx.doi.org/10.1016/j.ijpe.2013.04.055

[41] Chen, D.Q., Preston, D.S. and Xia, W. (2013) Enhancing Hospital Supply Chain Performance: A Relational View and Empirical Test. Journal of Operations Management, 31, 391-408. http://dx.doi.org/10.1016/j.jom.2013.07.012

[42] Lehoux, P., Daudelin, G., Williams-Jones, B., Denis, J.L. and Longo, C. (2014) How Do Business Model and Health Technology Design Influence Each Other? Insights from a Longitudinal Case Study of Three Academic Spin-Offs. Research Policy, 43, 1025-1038. http://dx.doi.org/10.1016/j.respol.2014.02.001

[43] Leitão, A., Cunha, P., Valente, F. and Marques, P. (2011) Roadmaps for Business Model Definition in Manufacturing Companies. Procedia CIRP, 7, 383-388. http://dx.doi.org/10.1016/j.procir.2013.06.003

[44] Wiesner, S., Padrock, P. and Thoben, K.D. (2014) Extended Product Business Model in Four Manufacturing Case Studies. Procedia CIRP, 16, 110-115. http://dx.doi.org/10.1016/j.procir.2014.01.014

[45] Copani, G., Molinari Tosatti, L., Lay, G., Schroeter, M. and Bueno, R. (2007) New Business Models Diffusion and Trends in European Machine Tool Industry. Proceedings of 40th CIRP International Manufacturing Systems Seminar, Liverpool, 30 May-1 June 2007.

[46] Urbani, A., Molinari-Tosatti, L. and Pasek, Z. (2002) Manufacturing Practices in Dynamic Markets: Reconfigurability to Enable a Service-Based Manufacturing Capacity Supply. Proceedings of the IMECE 2002: ASME International Mechanical Engineering Congress and Exposition, New Orleans, 17-22 November 2002, 575-582.

[47] Lay, G., Meier, H., Schramm, J. and Werding, A. (2003) Betreibenstattverkaufen—Stand und Perspektivenneuer Geschäft-modellefür den Maschinen—Und Anlagenbau. Industriemanagement, 19, 9-14.

[48] Copani. G. and Urgo, M. (2012) New Business Models and Configuration Approaches for Focused-Flexibility Manufacturing Systems. Procedia CIRP, 2, 10-15. http://dx.doi.org/10.1016/j.procir.2012.05.031

[49] Forza, C. and Salvador, F. (2008) Application Support to Product Variety Management. International Journal of Production Research, 46, 817-836. http://dx.doi.org/10.1080/00207540600818278

[50] Dong, B., Jia, H., Li, Z. and Dong, K. (2012) Implementing Mass Customization in Garment Industry. System Engineering Procedia, 3, 372-380. http://dx.doi.org/10.1016/j.sepro.2011.10.059 
Scientific Research Publishing (SCIRP) is one of the largest Open Access journal publishers. It is currently publishing more than 200 open access, online, peer-reviewed journals covering a wide range of academic disciplines. SCIRP serves the worldwide academic communities and contributes to the progress and application of science with its publication.

Other selected journals from SCIRP are listed as below. Submit your manuscript to us via either submit@scirp.org or Online Submission Portal.
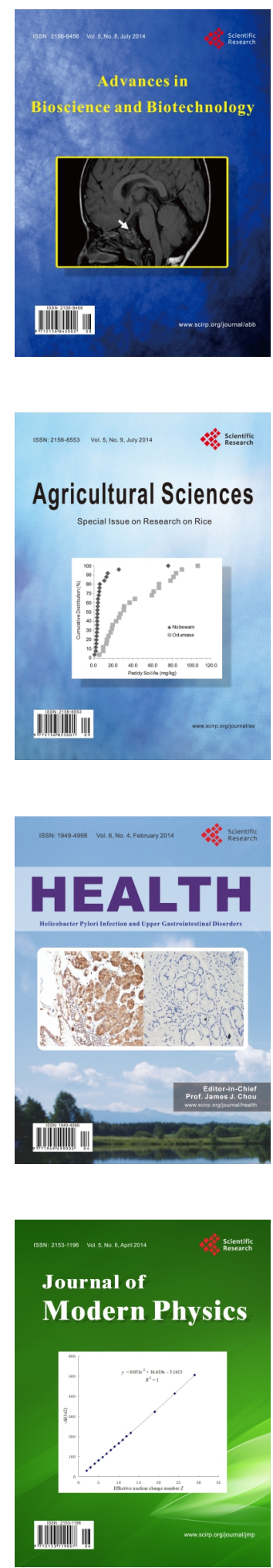
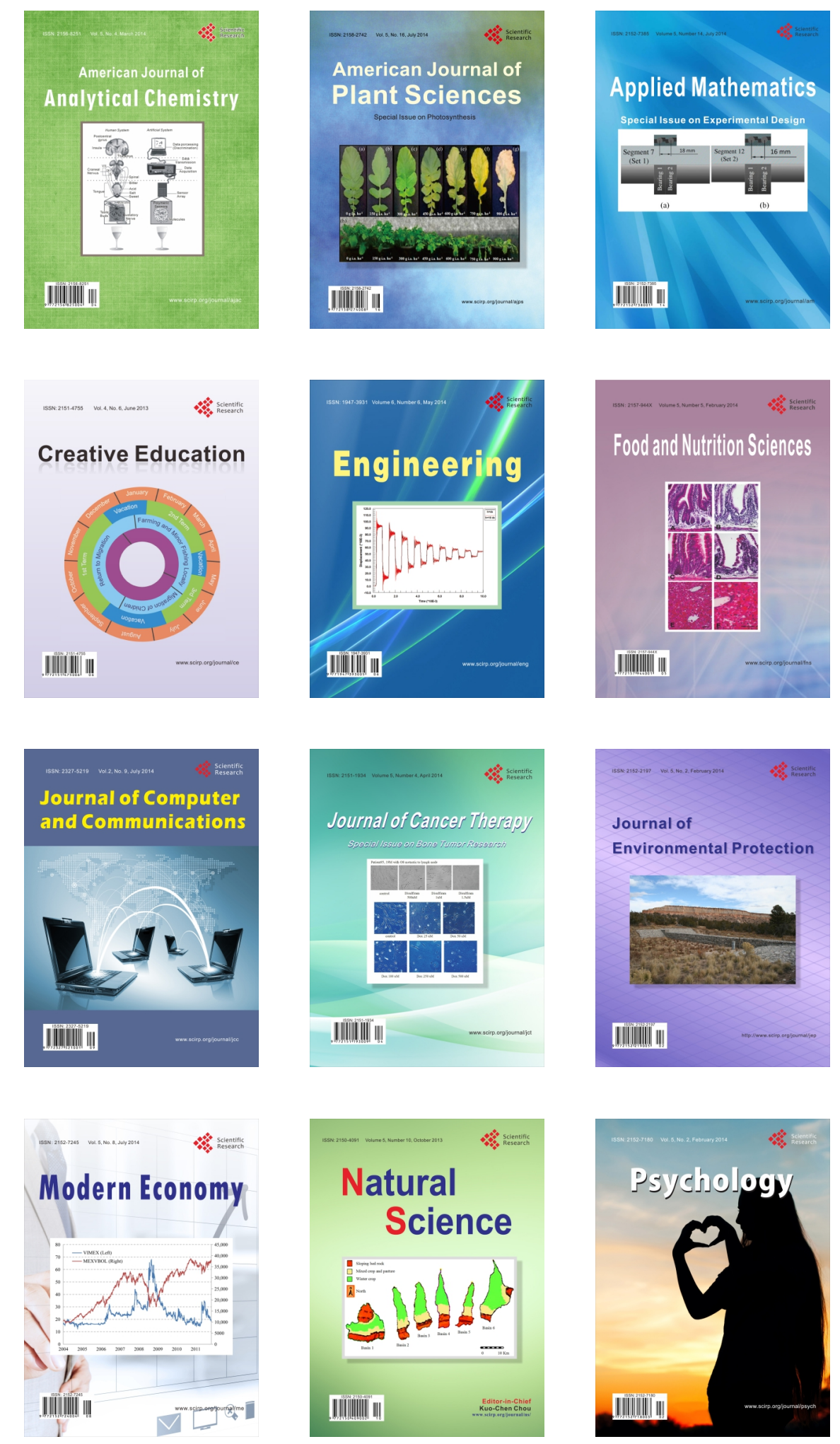